\title{
Describing CCFP(EM) programs in Canada: A national survey of program directors
}

\author{
Avik Nath, MD, MSc*; Krishan Yadav, MD, MSc*; Jeffrey J. Perry, MD, MSc*†‡
}

\begin{abstract}
CLINICIAN'S CAPSULE
What is known about the topic?

Little has been published on the structure and curricula of the Canadian College of Family Physicians Emergency Medicine [CCFP(EM)] programs across Canada.

What did this study ask?

Describe the major components of CCFP(EM) programs and how they are incorporated into curricula.

What did this study find?

Programs have similar clinical rotations, ultrasound, and simulation requirements. Variation exists in administrative structures, financial resources, academic projects, and competency-based curricula.

Why does this study matter to clinicians?

Our results will inform further development of the CCFP (EM) curricula.
\end{abstract}

\section{ABSTRACT}

Objectives: Enhanced skills training in emergency medicine through the Canadian College of Family Physicians, CCFP(EM), has existed since the 1980s. Accreditation standards define what every program "must" and "should" have, yet little is known on what is currently done across Canada. Our objectives were to 1) describe major components of CCFP(EM) programs and 2) determine how curricular components are taught.

Methods: After a rigorous development process (expert content development, cognitive reviews, and pilot testing), a survey questionnaire was administered to all $17 \operatorname{CCFP}(E M)$ program directors using a modified Dillman technique.

Results: All (17/17) program directors responded. Programs are similar in core clinical rotations conducted and provide ultrasound courses for basic skills (trauma, abdominal aortic aneurysm, intrauterine pregnancy). Variation exists for offering independent ultrasound certification (77\%), advanced scanning $(18 \%)$, and protected time for scanning (53\%). All programs utilize high fidelity simulation. Some programs use in situ simulation (18\%) and carry out a simulation boot camp (41\%). Most centres require an academic project, which is a quality assurance project (53\%) and/or a critical appraisal of the literature (59\%). Publication or national conference presentations are required by $12 \%$ of programs. Competency-based curricula include simulation for rare procedures $(88 \%)$, direct observations (65\%), and a "transition to practice" curriculum (24\%). All programs maintain strong connections to family medicine.

Conclusion: This study demonstrates the diverse structures of CCFP(EM) programs across Canada. Programs have similar clinical rotations, ultrasound, and simulation requirements. Variation exists in administrative structure and financial resources of programs, academic project requirements, and programs' competency-based curricula.

\section{RÉSUMÉ}

Introduction: II existe une formation avancée en médecine d'urgence (MU) pour les médecins de famille (CCMF [Certificat du Collège des médecins de famille du Canada] [MU]) depuis les années 1980. Dans les normes d'agrément, on définit ce qui " doit " et ce qui " devrait " être fait dans tous les programmes, mais on en connaît peu sur ce qui se fait actuellement partout au Canada. Aussi l'étude visait-elle : 1) à décrire les principaux éléments des programmes du CCMF (MU); et 2) à déterminer comment s'enseignent les différents éléments de programme.

Méthode: Après une démarche rigoureuse de conception (examen du contenu par des experts, analyse cognitive, essais pilotes), un questionnaire d'enquête a été envoyé à tous les directeurs de programme (17) du CCMF(MU) et recueilli selon une version modifiée de la méthode de Dillman.

Résultats: Tous (17/17) les directeurs de programme ont répondu au questionnaire. Des stages cliniques de base ainsi que des cours de base en échographie (trauma, anévrysme de l'aorte abdominale, grossesse intra-utérine) sont offerts dans tous les programmes. Toutefois, il existe des différences en ce qui concerne le certificat en vue de la pratique indépendante de l'échographie (77\%), les applications avancées de l'échographie (18\%) et les plages de temps consacré à l'étude de l'échographie (53\%). Dans tous les programmes, on recourt aux simulations réalistes; dans certains autres, on recourt aux simulations sur place $(18 \%)$ et on réalise des exercices intensifs de simulation (41\%). Dans la plupart des centres, les

From the *Department of Emergency Medicine and; †School of Epidemiology, Public Health, and Preventive Medicine, University of Ottawa, Ottawa, ON; and the ¥Ottawa Hospital Research Institute, Clinical Epidemiology Program, Ottawa, ON.

Correspondence to: Dr. Avik Nath, The Ottawa Hospital, Civic Campus, Room EM-206, 1053 Carling Avenue, Ottawa, ON K1Y 4E9, Canada; Email: anath@toh.ca 
étudiants doivent réaliser des travaux scientifiques, qui consistent en des projets d'assurance de la qualité (53\%) ou en une évaluation critique de la documentation (59\%). La publication d'articles ou des présentations dans le cadre de congrès nationaux sont exigées dans $12 \%$ des programmes. Les curriculums axés sur les compétences comprennent des séances de simulation d'interventions rares ( $88 \%)$, d'observation directe $(65 \%)$ ou de "transition vers la pratique " $(24 \%)$. Enfin, des liens étroits sont maintenus avec la médecine familiale dans tous les programmes.
Conclusions: Les résultats de l'étude démontrent l'existence de diverses structures dans les programmes de CCMF(MU) au Canada. Ceux-ci ont en commun les stages cliniques, l'échographie et les simulations, mais ils divergent quant aux structures administratives, aux ressources financières, aux exigences relatives aux travaux scientifiques et aux curriculums axés sur les compétences.

Keywords: CCFP(EM), EM program, enhanced skills, family medicine/emergency medicine

\section{INTRODUCTION}

Postgraduate training in emergency medicine (EM) in Canada is unique, with two distinct training pathways to achieve certification: a 1-year enhanced skills training program in EM following a 2-year family medicine training program through the Canadian College of Family Physicians, CCFP(EM); and a 5-year program through the Royal College of Physicians and Surgeons of Canada, FRCPC-EM (Royal College). Discussions regarding EM training in Canada have suggested a meeting between the two colleges and the Canadian Association of Emergency Physicians (CAEP) to occur in order to discuss the certification process. ${ }^{1}$ In June 2016, a joint effort by the Royal College, the College of Family Physicians of Canada (CFPC), and CAEP examined the unique role that each of these training programs have in providing emergency medical care in Canada. $^{2}$

The CFPC has offered enhanced skills training in EM since the 1980 s. $^{3}$ There are currently 17 national training sites for CCFP(EM) programs across Canada with approximately 118 eligible positions through the Canadian Resident Matching Service (CaRMS) in 2016-2017. ${ }^{4}$ The CFPC publishes The Red Book, which contains broad standards that describe the basic requirements for each program. ${ }^{5}$ These standards are used by the CFPC to accredit residency programs. While these accreditation standards define what every program "must" and "should" have, very little has been published on what the current structure and curriculum are for programs across the country. With the introduction of CanMEDS-Family Medicine in 2009, and the Triple C Competency-Based Curriculum in 2011, programs across the country have had to adapt and incorporate evolving elements into their curriculum. ${ }^{6}$

The objectives of the current study were to 1) describe major components of CCFP(EM) programs across Canada and 2) determine how curricular components are taught by programs across the country.

\section{METHODS}

\section{Study design and participants}

This study was an online English-language survey of CCFP(EM) program directors in Canada. (Appendix 1). All program directors were emailed an electronic survey on May 26, 2016, with follow-up emails sent every 2 weeks for 6 weeks. On June 6, 2016, at the CAEP annual conference held in Quebec City, an in-person verbal request to complete the survey was made to those who had not yet completed our survey. A \$50 coffee card was given to all program directors upon survey completion. This study was funded by the Department of Emergency Medicine internal grants program. Clinical rotation data were obtained from the CaRMS website. ${ }^{4}$

\section{Outcome measures}

The primary objective of the survey was to describe major components of $\mathrm{CCFP}(\mathrm{EM})$ programs. The survey questions investigated academic components and curricula of programs; financial and resource contributions to the program; organizational structure and administration of programs; as well as opinions of program directors on national issues affecting EM training. Content of the survey was based on national discussions held with program directors at biannual meetings and via electronic mail over the last 5 years.

\section{Questionnaire development}

We followed the modified Dillman technique incorporating expert review for content. ${ }^{7}$ The survey content was based on a review of national program director agenda 
items over the last 5 years and electronic mail communications between program directors related to components of the EM program (pre-survey). A draft survey was created) and pilot-tested using cognitive interviews to assess survey clarity, comprehensibility, and face validity. The cognitive interviews were conducted by providing the questionnaire to the EM program directors of the Royal College Program at the University of Ottawa. They were asked to read the questions aloud and express their thoughts and feeling regarding the survey questions in the presence of a research assistant. In addition, their body language such as facial expressions, pauses, and referrals to previously completed questions were observed and queried by the research assistant.

These program directors were asked to participate as they oversee similar EM training programs; however, they were not part of our target population. The final survey questionnaire consisted of four sections with a total of 63 questions and was administered online. It consisted of program structure and administration (18 questions); core curriculum components, including questions on ultrasound, simulation, academic project, academic day, exams, and competency-based assessment (32 questions); connection to family medicine (6 questions); and opinions of program directors as to the current state of $\mathrm{CCFP}(\mathrm{EM})$ programs (7 questions).

\section{Survey administration}

The final survey questionnaire was administered via Survey Monkey ${ }^{\circledR}$ (Survey Monkey Inc., San Mateo, California, USA) to all 17 CCFP(EM) Canadian program directors. A pre-notification email was sent out to all program directors a week prior to survey administration. A link to the electronic survey was sent via email on May 26, 2016, to each program director. Email reminders were sent every 2 weeks over a 6-week period. A reminder was given verbally to complete the electronic survey, during a national directors' program director meeting on June 6, 2016, at the CAEP annual conference in Quebec City.

The researchers coordinating this study were located at the University of Ottawa Department of Emergency Medicine and the Ottawa Hospital Research Institute in Ottawa, Ontario, Canada.

\section{Data analysis and sample size}

Descriptive statistics were used to summarize program director responses. Given the possible heterogeneity between programs, all $17 \mathrm{CCFP}(\mathrm{EM})$ program directors in Canada were surveyed. This study was reviewed by the Ottawa Health Science Network Research Ethics Board, and ethics approval was deemed exempt.

\section{RESULTS}

There was a $100 \%$ survey response rate.

\section{Program structure and administration}

A summary of program structure and administration is shown in Table 1. Seventy-six percent of programs have a single training stream (all residents complete the same rotations and have the same objectives, as opposed to a rural or community stream, which may differ in core clinical rotation type and location). Only one program has a specific rural training stream. Return of service residents (defined as family physicians in practice and returning as per Ministry of Health return of service eligibility) are accepted in only 59\% of training

\begin{tabular}{lr}
\hline Table 1. Program characteristics & \\
\hline Characteristic & Number (\%) \\
\hline Language of instruction & $3(17.6)$ \\
$\quad$ French & $14(82.4)$ \\
$\quad$ English & \\
Resident spots/year & $7(41.2)$ \\
$\quad 5-6$ & $7(41.2)$ \\
7-8 & $3(17.6)$ \\
$\quad>9$ & \\
Specific residency streams & $4(23.5)$ \\
$\quad$ Yes & \\
Types of residency streams & $4(30.8)$ \\
$\quad$ Community & $1(7.7)$ \\
Rural & \\
Consideration of "return of service" residency \\
applicants? \\
$\quad$ Yes \\
Number of "return of service" residency \\
spots in the last 5 years \\
$\quad 0$
\end{tabular}


programs. Administrative support is present in $100 \%$ of programs. The mean number of hours spent by the program administrator on each program per week is approximately equal to 0.3 full-time equivalents (i.e., about 13 hours/week). All program directors receive monetary support. Funding sources for both the program administrator and program director vary with contributions from both Departments of Family Medicine ( $41 \%$ and 59\%, respectively) and Emergency Medicine ( $41 \%$ and $35 \%$, respectively). A minority of programs have some other form of program director support, which is mostly limited to travel support (18\%), whereas some program directors get a shift reduction $(47 \%)$ and/or protected time $(41 \%)$ to carry out their duties. The mean number of hours of protected time was between 8 to 12 hours per week.

\section{Core curriculum}

\section{Clinical rotations}

Table 2 shows a summary of mandatory clinical rotations across programs. Six programs have tertiary care EM rotations combined with other curricula such as trauma, ultrasound, toxicology, anesthesia, or transition

\begin{tabular}{|c|c|c|}
\hline Mandatory rotations & $\begin{array}{l}\text { Number of } \\
\text { programs }\end{array}$ & $\begin{array}{c}\text { Median number } \\
\text { of rotations } \\
\text { (1 rotation }=4 \text { weeks) }\end{array}$ \\
\hline Emergency medicine & 17 & \\
\hline Tertiary & 17 & 4 \\
\hline Community & 14 & 1 \\
\hline Rural & 7 & 1 \\
\hline $\begin{array}{l}\text { Pediatric emergency } \\
\text { medicine }\end{array}$ & $16^{*}$ & 1 \\
\hline Anesthesia & 16 & 1 \\
\hline \multicolumn{3}{|l|}{ Intensive care } \\
\hline Adult & 17 & 2 \\
\hline Pediatrics & 2 & 1 \\
\hline $\begin{array}{l}\text { Cardiology/coronary care } \\
\text { unit }\end{array}$ & 11 & 1 \\
\hline $\begin{array}{l}\text { Orthopedics/sports } \\
\text { medicine }\end{array}$ & 11 & 1 \\
\hline Trauma & 11 & 1 \\
\hline Plastic surgery & $8^{\dagger}$ & 0.5 \\
\hline Toxicology & $4^{\ddagger}$ & 0.5 \\
\hline Ultrasound & 9 & 0.5 \\
\hline Elective & 16 & 1 \\
\hline \multicolumn{3}{|c|}{$\begin{array}{l}\text { *One program carries out pediatric emergency medicine longitudinally. } \\
\text { tOne program carries out plastic surgery longitudinally. } \\
\text { †Two programs carry out toxicology longitudinally. }\end{array}$} \\
\hline
\end{tabular}

to practice. Two programs carry out horizontal EM shifts. One program allows residents to do EM shifts on other rotations, whereas another program carries out pediatric EM shifts longitudinally during the year on residents' adult EM rotations.

\section{Ultrasound and simulation}

A summary of mandatory components of the ultrasound curriculum across programs is depicted in Table 3. All programs offer a basic ultrasound course that includes focused assessment with sonography for trauma (FAST), abdominal aortic aneurysm (AAA) screening, and determination of intrauterine pregnancy (IUP). Certification for ultrasound independent practice upon completion of the EM year is offered in $77 \%$ of programs. Advanced ultrasound training (e.g., gallbladder/central venous pressure/ophthalmologic/echocardiography) is mandatory in $18 \%$ of programs and is offered as an elective in $29 \%$ of programs. Table 4 summarizes various aspects of the simulation curriculum across programs. High-fidelity simulation sessions are offered in $100 \%$ of programs at a high-fidelity simulation centre.

\section{Academic project}

A summary of what comprises an "academic project" in each program, as required by the standards set out in The Red Book, is presented in Table 5. Most

\begin{tabular}{|c|c|}
\hline Curriculum item & Number (\%) \\
\hline $\begin{array}{l}\text { Introductory ultrasound course (focused } \\
\text { assessment with sonography for trauma (FAST), } \\
\text { abdominal aortic aneurysm (AAA) screening, and } \\
\text { determination of intrauterine pregnancy (IUP)) }\end{array}$ & $17(100)$ \\
\hline Ultrasound course for central lines & $9(52.9)$ \\
\hline $\begin{array}{l}\text { Ultrasound course for procedures (joint injections/ } \\
\text { thoracentesis/ paracentesis/ lumbar puncture/ } \\
\text { abscess) }\end{array}$ & $1(5.9)$ \\
\hline Ultrasound course for regional nerve blocks & $1(5.9)$ \\
\hline $\begin{array}{l}\text { Advanced ultrasound course (e.g., gallbladder/ } \\
\text { central venous pressure/ophthalmologic/ } \\
\text { echocardiography) }\end{array}$ & $3(17.6)$ \\
\hline Protected time for scanning shifts & $9(52.9)$ \\
\hline $\begin{array}{l}\text { Mandatory number of scanning images per } \\
\text { indication (e.g., } 50 \text { FAST scans per year) }\end{array}$ & $14(82.4)$ \\
\hline Any quality assurance (e.g., revision by staff of images) & $9(52.9)$ \\
\hline Ultrasound certification for independent practice & $13(76.5)$ \\
\hline Ultrasound exam & $10(58.8)$ \\
\hline $\begin{array}{l}\text { We don't offer our own course but pay for our } \\
\text { residents to do an ultrasound course elsewhere }\end{array}$ & $2(11.8)$ \\
\hline
\end{tabular}




\begin{tabular}{lc|}
\hline Table 4. Simulation curriculum & \\
\hline & Number \\
Curriculum item & $(\%)$ \\
\hline High-fidelity simulation & $17(100)$ \\
Low-fidelity simulation & $6(35.3)$ \\
In situ simulation & $3(17.6)$ \\
Simulation boot camp & $7(41.2)$ \\
Average hours of simulation per month & \\
$\quad<5$ hours & $10(58.8)$ \\
$\quad 5-10$ hours & $6(35.3)$ \\
$\quad 11-15$ hours & $1(5.9)$ \\
Simulation used as a formative tool & $15(88.2)$ \\
Simulation curriculum: & \\
$\quad$ Formal with well-developed cases that progress & $5(29.4)$ \\
through the year & \\
$\quad$ Formal with well-developed cases & $11(64.7)$ \\
$\quad$ No formal curriculum & $1(5.9)$
\end{tabular}

Table 5. Requirements of academic project

\begin{tabular}{|c|c|}
\hline Project type & $\begin{array}{c}\text { Number } \\
(\%)\end{array}$ \\
\hline Research proposal only & $3(17.7)$ \\
\hline Full research project* & $8(47.1)$ \\
\hline Quality improvement project ${ }^{\dagger}$ & $9(52.9)$ \\
\hline Presentation (grand rounds or journal club) & $7(41.2)$ \\
\hline Review of the literature in a systematic way & $10(58.8)$ \\
\hline $\begin{array}{l}\text { Critical appraisal/review of the literature (formal } \\
\text { systematic review) }\end{array}$ & $4(23.5)$ \\
\hline Other $^{\neq}$ & $1(5.9)$ \\
\hline \multicolumn{2}{|c|}{$\begin{array}{l}\text { *Including ethics, data collection, and analysis. } \\
\text { 'Without application to ethics board. } \\
\text { 'Educational and/or simulation curriculum development/EMS (emergency medical } \\
\text { services) rounds and protocol development. }\end{array}$} \\
\hline
\end{tabular}

commonly, $53 \%$ of programs recommend that residents complete a quality improvement project, and 59\% recommend a critical appraisal of the literature (not a full systematic review). A summary of resources and support mechanisms available for the academic project is shown in Table 6 . Only $12 \%$ of programs require residents to write up their project as an abstract for publication or presentation at a national conference.

\section{Academic program}

Protected teaching time for core EM concepts occurs in $94 \%$ of programs. Protected teaching time between 3 and 6 hours per week occurs in $71 \%$ of programs. The majority of programs $(71 \%)$ base their core sessions on "Priority Topics," as outlined by the CFPC. Core teaching sessions were mostly held jointly with the Royal

\begin{tabular}{|lc|}
\hline Table 6. Academic project resources & \\
\hline Resources & Number (\%) \\
\hline Timelines with deadlines & $14(82.4)$ \\
Supervisor & $14(82.4)$ \\
Methodologist & $5(29.4)$ \\
Research coordinator/administrative assistant & $8(47.1)$ \\
Funding & $4(23.5)$ \\
Protected academic time for research project & $4(23.5)$
\end{tabular}

College residents $47 \%$ of the time, whereas $18 \%$ of programs had sessions mostly separate from the Royal College residents. The primary textbook recommended by $88 \%$ of the programs to their residents was Tintinalli. ${ }^{8}$ All programs gave their residents written and oral exams in preparation for the Examination of Special Competence in Emergency Medicine held by the CFPC. Practice examinations given by programs to residents were formative in $77 \%$ of the programs.

\section{Competency-based curriculum}

Programs are undertaking various measures towards a competency-based curriculum: $88 \%$ of programs are using simulation to carry out uncommon procedures/ scenarios; $65 \%$ of programs are conducting direct observations; and only $24 \%$ of programs are tracking core competencies. Direct observations are carried out on clinical shifts (9 of 11 programs) or in the simulation lab (8 of 11 programs). Residents keep a logbook or equivalent in $53 \%$ of programs as a way to track core competencies/procedures during their year. Six of the nine programs carry this out electronically. One program requires residents to perform a certain number of specific competencies/procedures during their year. Only 24\% of programs currently have a transition to practice curriculum in place. Most of this incorporates a graduated level of responsibility over the year, as well as lectures on the transition to practice, including billing, medico-legal, managing learners, and managing the emergency department.

\section{Connection to family medicine}

Table 7 summarizes how programs maintain a connection to family medicine. The majority of program directors (94\%) felt that they had a close working relationship with their respective Department of Family Medicine (DFM) with $100 \%$ of program directors attending DFM enhanced skills resident promotion 


\begin{tabular}{lc}
\hline Table 7. Connection to family medicine & $\begin{array}{c}\text { Number } \\
\text { (\%) }\end{array}$ \\
\hline Activity & $11(64.7)$ \\
\hline $\begin{array}{l}\text { Having PGY-3 residents teaching at family medicine } \\
\text { academic day }\end{array}$ & $15(88.2)$ \\
$\begin{array}{l}\text { Having an optional "half-day back" family medicine } \\
\text { clinics ("half-day backs") }\end{array}$ & $5(29.4)$ \\
$\begin{array}{l}\text { Having social events with other family/enhanced skills } \\
\text { residents }\end{array}$ & $6(35.3)$ \\
$\begin{array}{l}\text { Presenting at family medicine research day } \\
\text { Having a mandatory rotation where residents do some } \\
\text { family medicine (e.g., rural or community rotation) }\end{array}$ & 2 (11.8) \\
\begin{tabular}{l} 
Other \\
\hline
\end{tabular} & $5(29.4)$ \\
\hline
\end{tabular}

committee meetings. No program had a "half-day back" (defined as returning to practice family medicine for half a day per week) as a mandatory part of their curriculum. In the past 5 years, only four programs have required a resident to complete a "half-day back" in family medicine.

\section{Program directors' opinions}

In the opinion of program directors, $82 \%$ felt that the majority of their graduates practice only EM and that $77 \%$ of their graduated residents worked in a community emergency department. A majority (82\%) felt that there was a need to increase the number of EM spots, and all indicated that a "half-day back" in family medicine should not be a mandatory part of the training program. Furthermore, $100 \%$ of program directors also stated that they did not feel that additional family medicine should be incorporated into the enhanced skills training year in EM. Finally, 69\% felt that the CFPC does not value the PGY-3 enhanced skills training in EM.

\section{DISCUSSION}

This is the first study to comprehensively describe the structure and curriculum of CCFP(EM) programs across Canada. The majority of programs train 5 to 8 residents per year with the exception of three programs in the province of Quebec, each training $>9$ residents. In total, programs train approximately 118 residents annually with enhanced skills in EM training. ${ }^{4}$ Nearly all programs have a single training stream where most rotations occur at a tertiary care centre. This differs from family medicine training, which typically has a mixture of urban, community, and rural training sites.
This may be because some core competencies that residents are required to achieve can reliably occur only on rotations at a regional referral site such as cardiology or trauma. Furthermore, only seven programs have a mandatory rural EM rotation. Future practice patterns of residents may be affected by this because residents are likely recruited and feel comfortable in a setting in which they have trained. More exposure to rural settings at any level encourages physicians to choose a rural practice. ${ }^{9,10}$ Further investigation, particularly in EM training, is needed to determine whether exposure to rural sites increases the retention of residents in smaller communities. Other initiatives have been instituted both provincially and federally to increase retention in rural sites, such as the return of a service program; however, there is little literature on the success or failure of these initiatives. ${ }^{8}$ Although the majority of programs accept the return of service residents, the number of residents actually trained through this program is small, and the success of this program in family medicine is mixed. ${ }^{11}$

The structure of the programs varies considerably across universities. There are differing levels of support given to programs with regards to finances, human resources, program director stipends, and protected time/shift reduction for program directors. Sources that contribute funding towards program assistant support and program director salary vary considerably between programs. Surprisingly, fewer than half of the programs identified their DFM as a contributor towards program assistant support, whereas just over half of the programs identified the DFM as providing financial program director support. This likely has direct implications regarding their ability to set policy over CCFP(EM) programs.

There are no national guidelines for ultrasound or simulation that state what each residency program must encompass with regards to specific curricula content. The Red Book does not explicitly state which point-ofcare ultrasound competencies are required for each program. ${ }^{5}$ Nevertheless, all programs offer an introductory level ultrasound course where the major pointof-care ultrasound indications are taught. There is considerable variation amongst programs regarding advanced ultrasound skills, quality assurance, and procedure-based ultrasound skills. While national position statements exist, such as those from CAEP, programs vary in what they offer as part of their core training program. ${ }^{12}$ Perhaps clearer guidelines and competencies will be forthcoming from the Royal 
College via its new Competence by Design (CBD) curriculum, which may be extrapolated by CCFP(EM) programs.

All programs offer high-fidelity simulation as part of their program. There is a considerable variation in time committed to simulation as well as curricular content between programs. The majority of programs currently use simulation as a formative tool, although this may change as programs start to incorporate more competency-based evaluation into their curriculum. Most programs describe their simulation curriculum as formal, with well-developed cases. However, the specific content and curriculum are decided upon individually by each program. A discussion is evolving nationally between program directors to formalize and share resources to deliver more standardized simulation content to residents in a structured way.

Program directors describe their relationship with their respective DFM as close. The majority of programs connect back to their respective family medicine programs through various teaching activities to family medicine residents. Only two programs make it mandatory for residents to do some form of family medicine practice in their additional year of training. Often during the accreditation process, programs are asked to demonstrate incorporation of family medicine during the enhanced skills year through a "half-day back." However, when asked, all program directors felt that a "half-day back" in family medicine should not be a mandatory part of their training. In the last 5 years, only five programs have had a resident do a "half-day back" in family medicine during their EM year. All program directors indicated that incorporating more family medicine in an already busy year was not advisable. Perhaps this is a result of most programs being based out of larger academic emergency departments where program directors often practice EM only. However, it stands to reason that in an already extremely busy year trying to teach residents core EM skills, additional family medicine training seems counterintuitive to what the enhanced skills year is designed for.

Stiell et al. identified many areas of future improvement in the domains of EM education scholarship and research. ${ }^{13}$ Perhaps unsurprisingly, there is a wide variation between programs in what is required for an academic project. The lack of a clear definition of what is considered an academic project in The Red Book likely contributes. ${ }^{5}$ Although the type of project varies nationally, the majority of programs do provide a structured process to conduct the academic project, including timelines and having a primary supervisor. Only two programs require their residents to submit an abstract or present their research at a national conference. Variability regarding access to a methodologist, having a research coordinator and funding, likely affects the type of project that each centre requires. These results are consistent with a survey completed by Calder et al. in 2015. ${ }^{14}$ As discussed by the authors in this paper of their survey, they highlighted marked diversity in residency programs' selfreport expectations, training, evaluation, infrastructure, and dissemination. They recommended that a clear path (i.e., explicit objectives and expectations) be identified for those interested in further research training.

There is considerable interaction between the Royal College and CCFP(EM) programs, with $47 \%$ of respondents stating that they mostly hold core academic sessions jointly. There seems to be a collegial and collaborative working relationship between Royal College and CCFP(EM) training programs at $100 \%$ of sites that have both programs. While the Collaborative Working Group on the Future of Emergency Medicine in Canada investigated the possibility of a unified training stream, there appears to be a collaborative and constructive relationship between the two programs. ${ }^{2}$

Since the introduction of the Triple C curriculum in 2011, EM programs across Canada have incorporated a variety of competency-based initiatives in their curricula. ${ }^{5}$ As the Royal College prepares to implement CBD for EM in 2018, there is an opportunity for significant collaboration between programs. Currently, $65 \%$ of programs require residents to obtain documented directed observations during clinical encounters or in the simulation lab. This may be an extension of family medicine programs, where field notes have been implemented as part of their Triple C curriculum. ${ }^{5}$ Residents are required to keep a logbook to track core competencies in $53 \%$ of programs. However, only one program asks residents to perform a number of specific competencies/procedures. Furthermore, only $24 \%$ of programs across the country have any sort of formal transition to practice curriculum. This is rather surprising considering that the enhanced skills year is focused on developing physicians who should be ready to practice in an emergency department immediately upon completion of their year. This partially may be due to a lack of standardized core competencies that define the enhanced skills year in 
EM. At present, with CBD discussions occurring at the Royal College level, CCFP(EM) program directors nationally are discussing whether a similar process to develop core competencies for the enhanced skills year should occur.

Finally, program directors across the country were asked about their opinions on various aspects of the EM year. Consistent with the Collaborative Working Group report, ${ }^{2}$ the majority of program directors felt that most residents graduating in the program practice only EM with no family medicine. Program directors felt that the majority of graduating residents worked in community emergency departments upon their completion of the enhanced skills year. Prior studies have shown that the majority of CCFP(EM) graduates practice EM in urban settings. ${ }^{2,15-17}$ There was unanimous agreement amongst program directors to not incorporate more family medicine during the year. Surprisingly, 69\% felt that the CFPC does not value the specialty training year in EM. A further 19\% felt that, although the CFPC was supportive of the training program, it was less supportive of residents only practicing EM following graduation. This perceived lack of support warrants further attention, given that up to a quarter of Canadian emergency physicians are dissatisfied with their occupation. ${ }^{18}$ Most program directors felt that there was a definite need to expand the enhanced skills training positions in EM to address population needs in their respective provinces.

\section{Next steps}

This survey was completed prior to the introduction of the new CBD curriculum by the Royal College. This will significantly change the way EM residency training is carried out in Royal College EM programs, with the majority of programs planning to implement CBD in 2018. Although most CCFP(EM) programs already have some form of competency assessments, this is likely to increase with the implementation of CBD. Repeating this survey in a few years' time will provide useful information on the effects of CBD on CCFP (EM) programs. Furthermore, an environmental scan of programs nationally would be helpful to fully detail what is currently being done in $\mathrm{CCFP}(\mathrm{EM})$ programs regarding competency training. This would better inform program directors on current practices and allow for further curriculum development and resource sharing between programs and colleges.

\section{LIMITATIONS}

Our study does have potential limitations. Survey questions were answered by a sole program director who may have limited knowledge of certain aspects of the program such as financial compensation. Another potential limitation is the relatively small number of CCFP(EM) programs across Canada; however, this limitation was minimized by our $100 \%$ survey response rate. Questions asked were often closed-ended and could have potentially been leading, but our survey design was rigorous to minimize this, through the cognitive interviews and piloting by Ottawa FRCPC program directors. Questions were asked that gave answers in categorical variables. This precluded us from reporting medians or means. Future surveys would benefit from asking questions with continuous variables as answers, to allow for better statistical quantification.

\section{CONCLUSION}

This study demonstrates the diverse structures of EM-enhanced skills training programs across Canada and is the first study to date that describes program structure, resources, and core curricula. Although there is considerable variation within each program, other components such as core clinical rotations, ultrasound training, and simulation have a minimal basic construct. A discussion should ensue to move towards harmonizing structure and core components of the program. However, a case could also be made that the strength of EM programs in Canada lies in the diverse components and practice settings that different programs have to offer. Program directors across the country can use this survey to inform whether standardization across programs is possible and which elements to include within their curriculum.

Acknowledgements: This study was supported by the University of Ottawa, Department of Emergency Medicine Internal Grant. We wish to thank Angela Marcantonio and Catherine Clement for their support during the study.

Competing interests: None declared.

\section{SUPPLEMENTARY MATERIALS}

To view supplementary material for this article, please visit https://doi.org/10.1017/cem.2018.374 


\section{REFERENCES}

1. Moore K, Lucky CA. Emergency medicine training in Canada. C7EM 1999;1(1):51-3.

2. Sinclair D, Abu-Laban RB, Toth P, et al., The Collaborative Working Group on the Future of Emergency Medicine in Canada (CWG-EM). Emergency medicine training and practice in Canada: celebrating the past and evolving for the future. Ottawa: The Canadian Association of Emergency Physicians, the College of Family Physicians Canada, and the Royal College of Physicians and Surgeons of Canada; 2016.

3. Elyas R. The birth of a new specialty: The history of emergency medicine in Canada. Clinical o Investigative Medicine 2007;30(4):supplement.

4. Canadian Resident Matching Service (CaRMS). 2017. Available at: https://www.carms.ca/en/ (accessed 20 December 2017).

5. The College of Family Physicians of Canada (CFPC). Specific standards for family medicine residency programs accredited by the College of Family Physicians of Canada; 2016. Available at: http://www.cfpc.ca/uploadedFiles/Red\% 20Book\%20English.pdf (accessed 20 December 2017).

6. Saucier D, Schipper S, Oandasan I, et al. Defining the three $\mathrm{Cs}$ of the triple $\mathrm{C}$ competency-based curriculum. The College of Family Physicians of Canada; 2017. Available at: http://www.cfpc.ca/uploadedFiles/Resources/Resource_Items/ Triple_C/3\%20Defining\%20the\%20Three\%20Cs\%20of\% 20the\%20Triple\%20C\%20Competency-based\%20Curriculum. pdf (accessed 20 December 2017).

7. Dillman DA. Mail and Internet surveys: the tailored design method, 2nd ed. Hoboken: Wiley; 2007.

8. Tintinalli JE, Stapczynski JS, Ma OJ, et al. Tintinalli's emergency medicine: a comprehensive study guide, 8th ed. New York: McGraw-Hill Education; 2015.

9. Pong RW, Heng D. Centre for Rural and Northern Health Research, Laurentian University. The link between rural medical education and rural medical practice location: literature review and synthesis; 2005. Available at: http:// documents.cranhr.ca/pdf/Physician_Planning_Unit_report_ Final.pdf (accessed 2017).

10. Steiner IP. Emergency medicine practice and training in Canada. CMA7 2003;168(12):1549-50.

11. Bosco C, Oandasan I. College of Family Physicians of Canada. Review of family medicine within rural and remote Canada: education, practice, and policy; 2016. Available at: http://www.cfpc.ca/uploadedFiles/Publications/News_Releases/ News_Items/ARFM_BackgroundPaper_Eng_WEB_FINAL. pdf (accessed 20 December 2017).

12. Henneberry J, Hanson A, Healey A, et al. Use of point of care sonography by emergency physicians. CFEM 2012;14(2): 106-12.

13. Stiell IG, Artz JD, Lang ES, et al. An environmental scan of academic emergency medicine at the 17 Canadian medical schools: why does this matter to emergency physicians? CFEM 2017;19(1):39-46.

14. Calder LA, Abu-Laban RB, Artz JD, et al. CAEP 2014 Academic Symposium: how to make research succeed in your department: promoting excellence in Canadian emergency medicine resident research. C7EM 2015; 17(5):591-9.

15. Varner C, Ovens H, Letovsky E, Borgundvaag B. Practice patterns of graduates of a CCFP(EM) residency program: a survey. Can Fam Physician 2012;58(7):e385-9.

16. Shepherd LG, Burden JK. A survey of one CCFP-EM program's graduates: their background, intended type of practice, and actual practice. CFEM 2005;7(5):315-20.

17. Chan BT. Do family physicians with emergency medicine certification actually practise family medicine? CMAf 2002;167(8):869-70.

18. Lloyd S, Streiner D, Shannon S. Burnout, depression, life and job satisfaction among Canadian emergency physicians. 7 Emerg Med 1994;12(4):559-65. 